\title{
Impact on Existing Transport Systems by Generated Traffic due to New Developments
}

\section{K. S. Weerasekera}

\begin{abstract}
Impact of future traffic generated due to a development activity was forecasted on available information at the time, for a proposed building complex in Colombo taking it as a study sample. Through this study a complete pre-assessment of 'in-coming' and 'out-going' vehicles which generates due to the proposed development was conducted before hand, and observed how it would affect the surrounding road network in future. Then it was also observed that, whether the impact was within, or outside the tolerable limits.
\end{abstract}

Once the proposed development was completed, and after few years of its operation, a validation was carried-out to assess the findings of the initial study which was conducted at the proposal stage of the development. The validation study results confirmed that the traffic generated due to the development was within tolerable limits of the surrounding road network as indicated in the initial study; hence the initial predictions were valid. Study also highlights the importance of development of local norms for traffic generating factors for different types of developments.

Keywords: $\quad$ Traffic Impact Assessments, TIA, Traffic Generation, Validation of TIA

\section{Introduction}

The impact of newly generated traffic due to a proposed development activity was studied taking the proposed administrative building complex for Aitken Spence Property Development Ltd. (proposal stage in 2005) at Vauxhall Street in Colombo 2 as a study sample. Through the initial study conducted in 2005 it was intended to carry-out a complete assessment of how 'in-coming' and 'out-going' vehicles due to the proposed development was to affect on the surrounding road network, and see whether the impact was within tolerable limits or not. Importance of this type of studies is emphasized in [1], and a validation of the initial study predictions is further conducted to confirm the initial study findings.

As indicated in Figure 1, the proposed administrative building (in 2005) for Aitken Spence Ltd., if constructed will add considerable amount of traffic during busy hours, to the already heavily trafficked union place, especially towards Hyde Park corner. Hence before granting approval for the building an initial traffic study was conducted in 2005 when the building was at its proposal stage. Initial study was conducted with the view to observe, if when constructed how it was going to affect the surrounding road network. Now in 2011, having been constructed and in full operation, a validation was carriedout to assess the initial study findings.

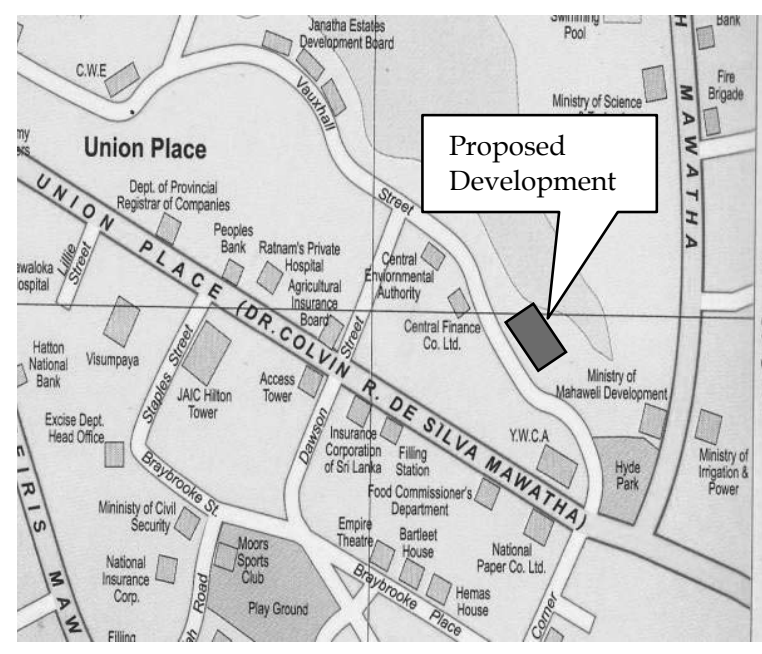

Figure 1 - Site Layout

\section{Methodology}

During the initial study site surveys were designed and specified to observe the existing traffic pattern in the surrounding road network, and it was expected to look into, how the

Eng. (Prof.) K. S. Weerasekera, BSc Eng (Moratuwa), MEngSc (UNSW), PhD (UNSW), FIE (Sri Lanka), CEng, IntPE(SL), MIE (Aust), CPEng, MIHT (UK), MASCE, Professor in Civil Engineering, Department of Civil Engineering, The Open University of Sri Lanka. 
proposed development was going to affect the surrounding road network in the future in advance, once the development is in full operation. Through traffic studies conducted along Union place, Darley road, and Vauxhall Street, morning, mid-day and evening peaks were identified. They were 8:00am to 9:00am, $12: 45 \mathrm{pm}$ to $1: 45 \mathrm{pm}$, and $4: 45 \mathrm{pm}$ to $5: 45 \mathrm{pm}$ respectively. Morning peak was not crucial since, once constructed the offices housed by the building will only come into operation after 9:30am. Hence the more crucial peaks of $12: 45 \mathrm{pm}$ to $1: 45 \mathrm{pm}$, and $4: 45 \mathrm{pm}$ to $5: 45 \mathrm{pm}$ were studied in detail.

In view to study the existing traffic situation in the surrounding road network two types of traffic surveys were conducted (i) Manual Classified Counts (MCC) of 12 hour duration (7:00am to 7:00 pm) on the surrounding roads (at mid-blocks D1, D2 and D3, shown in Figure 2) and (ii) Turning Movement Surveys (TMS) at the intersections A, B and C shown in Figure 2.

\section{Calculation and Analysis}

For the traffic surveys vehicles were categorized into 5 typical types as described in Table 1 for the calculation of traffic flows, and subsequently to check with service flow capacities. Passenger Car Unit (PCU) factors for each category for different lane conditions on level terrain are indicated in Table 1.

Table 1 - Types of Vehicles and Relevant Passenger Car Unit (PCU) Factors

\begin{tabular}{|l|c|c|}
\hline \multicolumn{1}{|c|}{ Vehicle Type } & \multicolumn{2}{|c|}{ PCU } \\
\cline { 2 - 3 } & 2-way, 2-lane & Multi-lane \\
\hline Type 1 - Passenger cars, jeeps, SUVs, pick-ups, single and double \\
cabs and small vans. & 1.0 & 1.0 \\
\hline Type 2 - Three-wheelers & 0.5 & 0.5 \\
\hline Type 3 - Small trucks, large vans and small buses & 2.0 & 1.5 \\
\hline Type 4 - Medium trucks and standard buses & 2.2 & 1.7 \\
\hline $\begin{array}{l}\text { Type 5 - Heavy trucks, large buses, tourist coaches and multi axle } \\
\text { vehicles }\end{array}$ & 2.8 & 2.2 \\
\hline
\end{tabular}

(Source: [2] Geometric Design Standards, RDA )

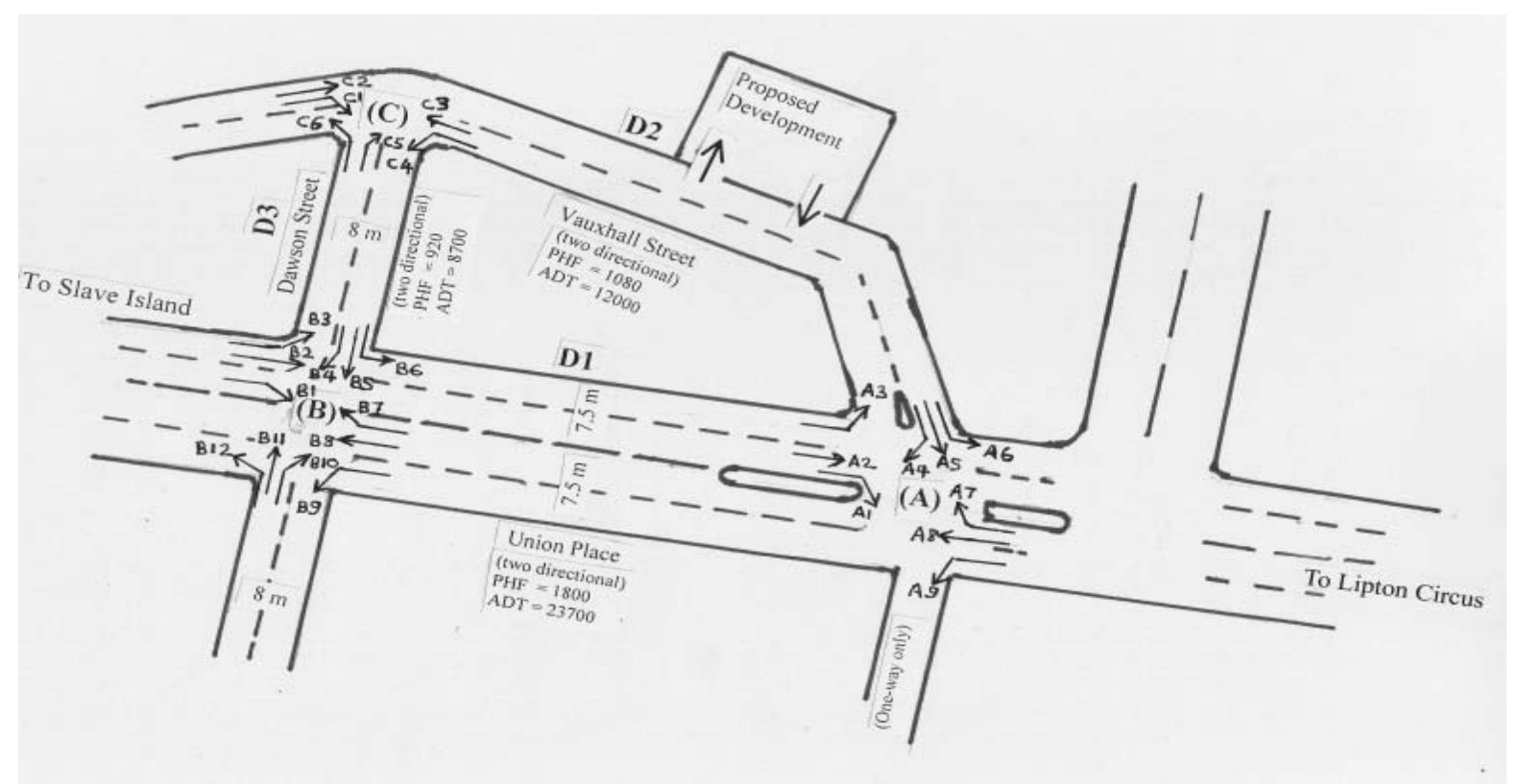

Figure 2 - Site Layout and Turning Movements 


\section{1 $\quad$ Generated Traffic}

Although it is known that traffic generation is a function of the land use and type of development, some broad assumptions had to be made due to lack of local norms [3]. Hence following method for traffic forecasting was adopted in the study.

The proposed development will have 100 parking bays (as per UDA guidelines [5]), and this value was used for traffic generation computations. Under the broader assumptions that when the proposed development is in full operation, that every 15 minutes $25 \%$ of bays gets a new vehicle and the earlier vehicle leaves the bay. This is probably an estimation of the higher order, since in practice chances of vehicles parked for longer durations are more, with vehicles of the office staff and customers/visitors spending more than 45 minutes at business is higher. Hence a higher factor of safety is assumed. Therefore every 15 minutes 25 vehicles arrive and 25 vehicles depart the development area.

Figure 3 indicates 'in' and 'out' movements of vehicles around the development area. Assuming a 50:50 directional split, Vauxhall Street will have an additional traffic of $100 \mathrm{vph}$ (maximum).

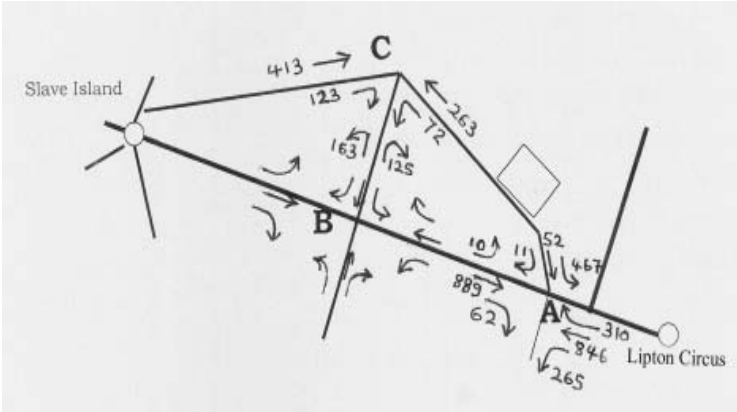

Figure 4 - Current Day-time Peak Flows

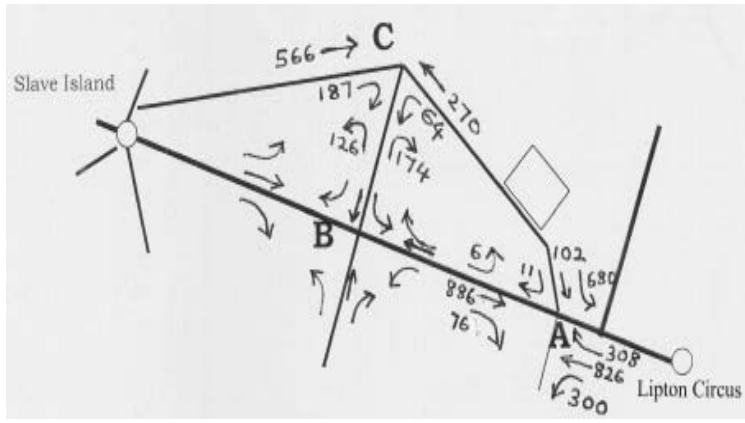

Figure 6 - Current Evening Peak Flows

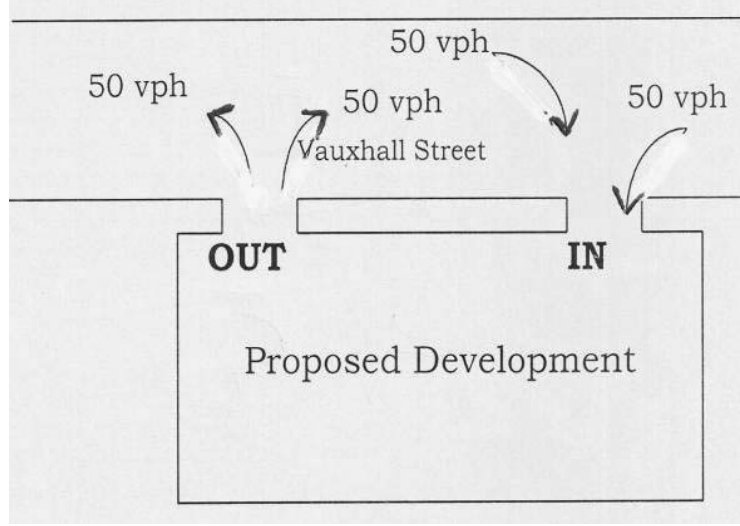

Figure 3 - Vehicular 'in' and 'out' Movement

\subsection{Current Traffic (i.e., in 2005)}

Current peak hour traffic movements during day-time and evening peaks at intersections $\mathrm{A}$, $\mathrm{B}$ and $\mathrm{C}$ are shown in Figures 4 and 6.

\subsection{Future Traffic}

Based on current and generated traffic due to proposed development, future traffic was computed. Peak hour movements for future traffic during day-time and evening at intersections A, B and C are shown in Figures 5 and 7.

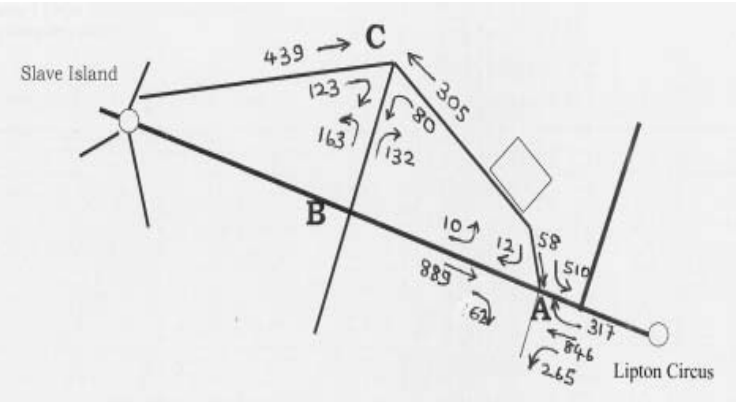

Figure 5 - Future Day-time Peak Flows

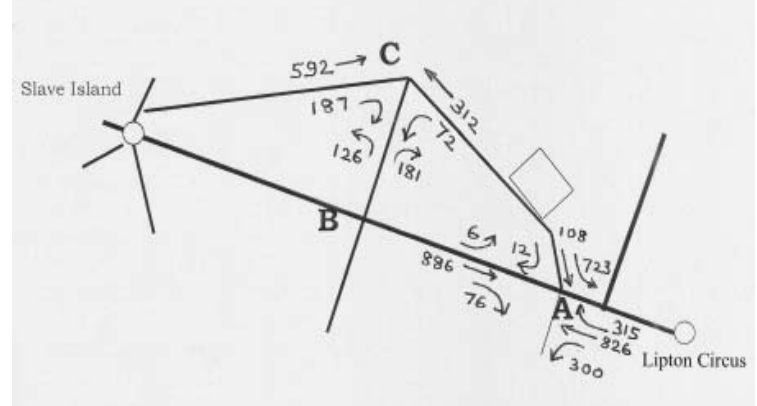

Figure 7 - Future Evening Peak Flows 
Table 2 - Peak Hour Traffic Flow Projections (Turning Movements) Intersection at Hyde Park Corner (A)

\begin{tabular}{|c|c|c|c|c|c|c|c|c|c|c|}
\hline \multirow{2}{*}{$\begin{array}{l}\text { Peak } \\
\text { Hour }\end{array}$} & \multirow{2}{*}{$\frac{\text { Intersection }}{\text { Movement }}$} & \multicolumn{9}{|c|}{ Intersection - A } \\
\hline & & $\overline{\mathrm{A} 1}$ & A2 & A3 & $\mathrm{A} 4$ & A5 & A6 & A7 & A8 & A9 \\
\hline \multirow{5}{*}{$\begin{array}{l}\text { Daytime } \\
\text { Peak } \\
(12: 45 \text { to } \\
13: 45)\end{array}$} & $\begin{array}{l}\text { Current Peak } \\
\text { Hour Volume }\end{array}$ & 62 & 889 & 10 & 11 & 52 & 467 & 310 & 846 & 265 \\
\hline & $\begin{array}{l}\text { Share contribution } \\
\text { from development }\end{array}$ & 0 & 0 & 0.005 & 0.0199 & 0.1134 & 0.8667 & 0.133 & 0 & 0 \\
\hline & Added volume & 0 & 0 & 0 & 1 & 6 & 43 & 7 & 0 & 0 \\
\hline & $\begin{array}{l}\text { Predicted Peak } \\
\text { Hour Volume }\end{array}$ & 62 & 889 & 10 & 12 & 58 & 510 & 317 & 846 & 265 \\
\hline & $\%$ increase & $0 \%$ & $0 \%$ & $3 \%$ & $9 \%$ & $11 \%$ & $9 \%$ & $2 \%$ & $0 \%$ & $0 \%$ \\
\hline \multirow{5}{*}{$\begin{array}{l}\text { Evening } \\
\text { Peak } \\
(16: 45 \text { to } \\
17: 45)\end{array}$} & $\begin{array}{l}\text { Current Peak } \\
\text { Hour Volume }\end{array}$ & 76 & 886 & 6 & 11 & 102 & 680 & 308 & 826 & 300 \\
\hline & $\begin{array}{l}\text { Share contribution } \\
\text { from development }\end{array}$ & 0 & 0 & 0.005 & 0.0199 & 0.1134 & 0.8667 & 0.133 & 0 & 0 \\
\hline & Added volume & 0 & 0 & 0 & 1 & 6 & 43 & 7 & 0 & 0 \\
\hline & $\begin{array}{l}\text { Predicted Peak } \\
\text { Hour Volume }\end{array}$ & 76 & 886 & 6 & 12 & 108 & 723 & 315 & 826 & 300 \\
\hline & $\%$ increase & $0 \%$ & $0 \%$ & $4 \%$ & $9 \%$ & $6 \%$ & $6 \%$ & $2 \%$ & $0 \%$ & $0 \%$ \\
\hline
\end{tabular}

Table 3 - Peak Hour Traffic Flow Projections (Turning Movements) Intersection at Vauxhall Street / Dawson Street (C)

\begin{tabular}{|l|l|c|c|c|c|c|c|}
\hline \multirow{2}{*}{$\begin{array}{l}\text { Peak } \\
\text { Hour }\end{array}$} & Intersection & \multicolumn{6}{|c|}{ Intersection - C } \\
\cline { 2 - 9 } & Movement & C1 & C2 & C3 & C4 & C5 & C6 \\
\hline \multirow{4}{*}{$\begin{array}{l}\text { Daytime } \\
\text { Peak }\end{array}$} & $\begin{array}{l}\text { Current Peak } \\
\text { Hour Volume }\end{array}$ & 123 & 413 & 263 & 72 & 125 & 163 \\
\cline { 2 - 9 }$(12: 45$ to & $\begin{array}{l}\text { Share contribution } \\
\text { from development }\end{array}$ & 0 & 0.52 & 0.833 & 0.1671 & 0.1395 & 0 \\
\cline { 2 - 9 } \begin{tabular}{l} 
Added volume \\
\cline { 2 - 9 }
\end{tabular} & $\begin{array}{l}\text { Predicted Peak } \\
\text { Hour Volume }\end{array}$ & 123 & 439 & 305 & 80 & 132 & 163 \\
& $\%$ increase & $0 \%$ & $6 \%$ & $16 \%$ & $12 \%$ & $6 \%$ & $0 \%$ \\
\hline \multirow{3}{*}{$\begin{array}{l}\text { Evening } \\
\text { Peak }\end{array}$} & $\begin{array}{l}\text { Current Peak } \\
\text { Hour Volume }\end{array}$ & 187 & 586 & 270 & 64 & 174 & 126 \\
\cline { 2 - 9 }$(16: 45$ to & $\begin{array}{l}\text { Share contribution } \\
\text { from development }\end{array}$ & 0 & 0.52 & 0.833 & 0.1671 & 0.1395 & 0 \\
\cline { 2 - 9 } & Added volume & 0 & 26 & 42 & 8 & 7 & 0 \\
\cline { 2 - 9 } & $\begin{array}{l}\text { Predicted Peak } \\
\text { Hour Volume }\end{array}$ & 187 & 592 & 312 & 72 & 181 & 126 \\
\cline { 2 - 9 } & $\%$ increase & $0 \%$ & $5 \%$ & $15 \%$ & $13 \%$ & $4 \%$ & $0 \%$ \\
\hline
\end{tabular}

\section{Initial Study Recommendations}

The proposed development will have an impact of additional $100 \mathrm{vph}$ at its peak and lesser contribution during other times to adjoining Vauxhall Street and the surrounding road network. The effect of this contribution on the surrounding road network during the peak hours is indicated in Figures 5, 7 and Tables 2 and 3.

Table 2 indicates the increased vehicular flows of different turning movements during daytime and evening peak hours, at adjoining 
intersections due to the proposed development. The overall percentage increase on traffic on Vauxhall Street is around 9\%, which is below the threshold level, for twoway roads that are operating under service flow capacity [4]. The percentage increase on traffic on other surrounding roads is much lesser and impact is minimal, so that the proposed development could be granted approval subjected to the satisfaction of other requirements laid in the UDA guidelines [5].

\section{Validation}

A validation study was conducted in March 2011, two years after completion of the building and when it is in full operation. Vehicle entry and exit gates were monitored over a period of 5 days from Monday to Friday during an average week (Appendices A and B).

After recording vehicles entering and exiting times at both entry and exit gates for 5 days from 7:00AM to 7:00PM, five week-day averages of entry and exit times were computed and figures were listed at 15 minute intervals (Appendices A and B).

It was observed that highest 'in and out' movement took place in the morning between 8:00AM to 9:00AM which included 81 entering vehicles and 39 exiting vehicles from the premises. That will lead to 120 additional vehicles on Vauxhall Street during morning peak, an increase of 20 vehicles than initial prediction of 100 vehicles in the traffic impact assessment.

Similarly during the evening, between $4: 45 \mathrm{PM}$ to 5:45PM, 84 vehicles exited while 35 vehicles entered. Comparatively mid-day in and out movements were not as higher as expected in the initial study. That will lead to 119 additional vehicles on Vauxhall Street during evening peak. This is an increase of 19 vehicles than initial prediction of 100 vehicles in the traffic impact assessment.

\section{Conclusion}

The outcome of the validation study of the initial traffic impact assessment emphasise the importance of development of local norms to indicate traffic generation factors for different types of developments separately, as discussed in [3]. Due to lack of local norms to indicate accurate traffic generation factors for different types of developments such as office complexes, business establishments, hotel developments, hospitals, recreational areas etc., it is hard to forecast accurate future traffic figures that will generate due to the proposed new developments. Hence further studies on traffic generation due to new developments, and development of local norms on traffic generation for different types of developments are recommended.

\section{Acknowledgment}

Author wishes to acknowledge Mr. S. Kokulkanth and his team of surveyors who assisted in field surveys, and also thank Mr. Sampath Godawitharana DGM Aitken Spence Property Development Ltd., for his kind assistance during validation stage.

\section{References}

1. Weerasekera, K. S., An Introduction to Traffic Engineering, Incolour (Pvt) Ltd, Colombo, 2009.

2. Geometric Design Standards of Roads: Road Design Manual, Road Development Authority of Sri Lanka, 1998.

3. Weerasekera, K. S., 'Some Problems Associated with Development of Traffic Impact Assessments in Developing Countries', Proceedings of the First Brunei International Conference on Engineering and Technology, Institute of Technology Brunei, Bandar Seri Begawan, Brunei Darussalam, 9-11 October 2001.

4. Salter, R. J and Hounsell, N. B, Highway Traffic Analysis and Design, MACMILLAN Press Ltd, London, 1996.

5. UDA Planning and Building Regulations, Vol. 2, City of Colombo Development Plan, Published by Urban Development Authority, Ministry of Housing and Urban Development Authority, Sethsiripaya, Battaramulla, March 1999. 
Appendix - A

Entry Gate - (Gate No: 1)

\begin{tabular}{|c|c|c|c|c|c|c|c|}
\hline Time & $\begin{array}{c}\text { 14th Mar } \\
\text { Mon }\end{array}$ & $\begin{array}{l}\text { 15th } \\
\text { Mar } \\
\text { Tue }\end{array}$ & $\begin{array}{l}\text { 16th } \\
\text { Mar } \\
\text { Wed }\end{array}$ & $\begin{array}{l}\text { 17th } \\
\text { Mar } \\
\text { Thu }\end{array}$ & $\begin{array}{l}\text { 18th } \\
\text { Mar } \\
\text { Fri }\end{array}$ & Average & $\begin{array}{c}\text { Hourly } \\
\text { Total }\end{array}$ \\
\hline $7: 00-7: 15$ & 0 & 6 & 1 & 4 & 0 & 2 & \\
\hline $7: 15$ - 7:30 & 16 & 8 & 9 & 10 & 9 & 10 & \\
\hline $7: 30$ - 7:45 & 5 & 18 & 14 & 8 & 14 & 12 & \\
\hline $7: 45-8: 00$ & 15 & 3 & 29 & 11 & 8 & 13 & 38 \\
\hline $8: 00-8: 15$ & 37 & 18 & 16 & 29 & 23 & 25 & 60 \\
\hline $8: 15$ - 8:30 & 23 & 22 & 29 & 10 & 20 & 21 & 70 \\
\hline $8: 30-8: 45$ & 22 & 7 & 15 & 24 & 17 & 17 & 76 \\
\hline $8: 45$ - 9:00 & 21 & 17 & 9 & 23 & 21 & 18 & 81 \\
\hline 9:00 - 9:15 & 12 & 22 & 19 & 17 & 16 & 17 & 73 \\
\hline $9: 15$ - 9:30 & 8 & 3 & 20 & 8 & 17 & 11 & 64 \\
\hline $9: 30-9: 45$ & 17 & 13 & 8 & 10 & 6 & 11 & 57 \\
\hline $9: 45-10: 00$ & 9 & 13 & 6 & 15 & 11 & 11 & 50 \\
\hline 10:00 - 10:15 & 4 & 5 & 10 & 11 & 11 & 8 & 41 \\
\hline 10:15 - 10:30 & 11 & 21 & 13 & 11 & 9 & 13 & 43 \\
\hline 10:30 - 10:45 & 13 & 4 & 6 & 8 & 15 & 9 & 41 \\
\hline 10:45 - 11:00 & 17 & 18 & 9 & 9 & 7 & 12 & 42 \\
\hline 11:00 - 11:15 & 14 & 10 & 8 & 7 & 8 & 9 & 44 \\
\hline $11: 15$ - 11:30 & 4 & 14 & 11 & 14 & 15 & 12 & 42 \\
\hline $11: 30$ - 11:45 & 16 & 5 & 8 & 7 & 11 & 9 & 42 \\
\hline 11:45 - 12:00 & 9 & 10 & 16 & 19 & 12 & 13 & 44 \\
\hline 12:00 - 12:15 & 12 & 2 & 7 & 7 & 11 & 8 & 42 \\
\hline $12: 15$ - 12:30 & 13 & 4 & 17 & 7 & 10 & 10 & 41 \\
\hline $12: 30$ - 12:45 & 14 & 21 & 12 & 10 & 18 & 15 & 46 \\
\hline 12:45 - 13:00 & 10 & 9 & 7 & 6 & 8 & 8 & 41 \\
\hline 13:00 - 13:15 & 10 & 11 & 11 & 3 & 16 & 10 & 43 \\
\hline 13:15 - 13:30 & 6 & 12 & 11 & 20 & 5 & 11 & 44 \\
\hline 13:30 - 13:45 & 11 & 7 & 7 & 9 & 11 & 9 & 38 \\
\hline $13: 45-14: 00$ & 2 & 6 & 10 & 10 & 5 & 7 & 37 \\
\hline 14:00 - 14:15 & 11 & 13 & 11 & 5 & 5 & 9 & 35 \\
\hline 14:15 - 14:30 & 11 & 12 & 8 & 6 & 2 & 8 & 32 \\
\hline $14: 30$ - 14:45 & 13 & 12 & 9 & 11 & 10 & 11 & 34 \\
\hline $14: 45$ - 15:00 & 4 & 10 & 13 & 0 & 8 & 7 & 35 \\
\hline 15:00 - 15:15 & 19 & 6 & 8 & 11 & 10 & 11 & 37 \\
\hline $15: 15$ - 15:30 & 10 & 8 & 6 & 10 & 2 & 7 & 36 \\
\hline $15: 30$ - 15:45 & 11 & 8 & 6 & 5 & 11 & 8 & 33 \\
\hline $15: 45$ - 16:00 & 16 & 16 & 10 & 11 & 8 & 12 & 38 \\
\hline 16:00 - 16:15 & 11 & 12 & 10 & 8 & 7 & 10 & 37 \\
\hline $16: 15$ - 16:30 & 10 & 8 & 12 & 1 & 6 & 7 & 37 \\
\hline $16: 30$ - 16:45 & 6 & 13 & 8 & 6 & 10 & 9 & 38 \\
\hline $16: 45$ - 17:00 & 4 & 12 & 9 & 6 & 6 & 7 & 33 \\
\hline $17: 00$ - 17:15 & 13 & 11 & 9 & 5 & 9 & 9 & 33 \\
\hline $17: 15$ - 17:30 & 12 & 23 & 13 & 5 & 12 & 13 & 38 \\
\hline $17: 30$ - 17:45 & 6 & 7 & 7 & 1 & 3 & 5 & 35 \\
\hline $17: 45$ - 18:00 & 2 & 3 & 4 & 2 & 6 & 3 & 31 \\
\hline 18:00 - 18:15 & 6 & 1 & 3 & 4 & 3 & 3 & 25 \\
\hline 18:15 - 18:30 & 4 & 1 & 1 & 3 & 1 & 2 & 14 \\
\hline $18: 30$ - 18:45 & 4 & 1 & 4 & 2 & 5 & 3 & 12 \\
\hline $18: 45$ - 19:00 & 0 & 2 & 4 & 2 & 5 & 3 & 11 \\
\hline
\end{tabular}




\section{Appendix - B}

Exit Gate - (Gate No: 2)

\begin{tabular}{|c|c|c|c|c|c|c|c|}
\hline Time & $\begin{array}{l}\text { 14th } \\
\text { Mar } \\
\text { Mon }\end{array}$ & $\begin{array}{l}\text { 15th } \\
\text { Mar } \\
\text { Tue }\end{array}$ & $\begin{array}{l}\text { 16th } \\
\text { Mar } \\
\text { Wed }\end{array}$ & $\begin{array}{l}\text { 17th } \\
\text { Mar } \\
\text { Thu }\end{array}$ & $\begin{array}{l}\text { 18th } \\
\text { Mar } \\
\text { Fri }\end{array}$ & Average & $\begin{array}{c}\text { Hourly } \\
\text { Total }\end{array}$ \\
\hline $7: 00-7: 15$ & 0 & 2 & 4 & 0 & 2 & 2 & \\
\hline $7: 15-7: 30$ & 5 & 5 & 3 & 1 & 4 & 4 & \\
\hline 7:30 - 7:45 & 18 & 4 & 2 & 4 & 6 & 7 & \\
\hline $7: 45-8: 00$ & 2 & 7 & 8 & 2 & 8 & 5 & 17 \\
\hline $8: 00-8: 15$ & 12 & 3 & 12 & 13 & 14 & 11 & 27 \\
\hline $8: 15$ - 8:30 & 12 & 8 & 10 & 8 & 8 & 9 & 32 \\
\hline $8: 30-8: 45$ & 10 & 10 & 10 & 6 & 11 & 9 & 35 \\
\hline $8: 45$ - 9:00 & 12 & 9 & 13 & 6 & 7 & 9 & 39 \\
\hline 9:00 - 9:15 & 4 & 10 & 9 & 18 & 8 & 10 & 38 \\
\hline $9: 15$ - 9:30 & 17 & 9 & 5 & 6 & 11 & 10 & 38 \\
\hline $9: 30-9: 45$ & 8 & 13 & 8 & 5 & 7 & 8 & 37 \\
\hline $9: 45-10: 00$ & 13 & 17 & 9 & 8 & 9 & 11 & 39 \\
\hline 10:00 - 10:15 & 9 & 8 & 14 & 9 & 3 & 9 & 38 \\
\hline 10:15 - 10:30 & 9 & 14 & 10 & 16 & 20 & 14 & 42 \\
\hline 10:30 - 10:45 & 6 & 10 & 12 & 3 & 6 & 7 & 41 \\
\hline 10:45 - 11:00 & 15 & 8 & 16 & 3 & 9 & 10 & 40 \\
\hline 11:00 - 11:15 & 17 & 11 & 14 & 12 & 11 & 13 & 44 \\
\hline 11:15 - 11:30 & 21 & 10 & 6 & 13 & 13 & 13 & 43 \\
\hline 11:30 - 11:45 & 15 & 14 & 15 & 10 & 20 & 15 & 51 \\
\hline $11: 45$ - 12:00 & 11 & 14 & 13 & 9 & 3 & 10 & 50 \\
\hline $12: 00$ - 12:15 & 12 & 9 & 10 & 5 & 14 & 10 & 47 \\
\hline $12: 15$ - 12:30 & 15 & 12 & 18 & 12 & 10 & 13 & 48 \\
\hline $12: 30$ - 12:45 & 12 & 11 & 22 & 17 & 10 & 14 & 48 \\
\hline $12: 45-13: 00$ & 1 & 15 & 14 & 11 & 12 & 11 & 48 \\
\hline 13:00 - 13:15 & 1 & 11 & 5 & 6 & 11 & 7 & 45 \\
\hline 13:15 - 13:30 & 0 & 10 & 16 & 10 & 19 & 11 & 43 \\
\hline 13:30 - 13:45 & 4 & 9 & 9 & 17 & 5 & 9 & 37 \\
\hline $13: 45-14: 00$ & 13 & 15 & 16 & 14 & 16 & 15 & 41 \\
\hline 14:00 - 14:15 & 3 & 7 & 13 & 5 & 6 & 7 & 41 \\
\hline 14:15 - 14:30 & 19 & 8 & 7 & 9 & 7 & 10 & 40 \\
\hline 14:30 - 14:45 & 11 & 8 & 12 & 11 & 9 & 10 & 42 \\
\hline $14: 45-15: 00$ & 3 & 9 & 9 & 11 & 15 & 9 & 36 \\
\hline $15: 00$ - 15:15 & 4 & 20 & 8 & 3 & 6 & 8 & 38 \\
\hline $15: 15-15: 30$ & 8 & 16 & 10 & 7 & 7 & 10 & 37 \\
\hline 15:30 - 15:45 & 17 & 12 & 10 & 11 & 10 & 12 & 39 \\
\hline 15:45 - 16:00 & 1 & 14 & 12 & 13 & 15 & 11 & 41 \\
\hline 16:00 - 16:15 & 20 & 12 & 11 & 7 & 11 & 12 & 45 \\
\hline 16:15 - 16:30 & 15 & 11 & 12 & 9 & 13 & 12 & 47 \\
\hline 16:30 - 16:45 & 5 & 6 & 9 & 6 & 13 & 8 & 43 \\
\hline $16: 45-17: 00$ & 10 & 12 & 14 & 6 & 12 & 11 & 43 \\
\hline 17:00 - 17:15 & 9 & 24 & 22 & 23 & 25 & 21 & 51 \\
\hline $17: 15$ - 17:30 & 22 & 25 & 24 & 20 & 34 & 25 & 64 \\
\hline 17:30 - 17:45 & 26 & 19 & 25 & 19 & 16 & 21 & 77 \\
\hline $17: 45-18: 00$ & 26 & 14 & 19 & 7 & 22 & 18 & 84 \\
\hline 18:00 - 18:15 & 17 & 9 & 17 & 16 & 17 & 15 & 79 \\
\hline 18:15 - 18:30 & 14 & 4 & 10 & 10 & 8 & 9 & 63 \\
\hline 18:30 - 18:45 & 17 & 11 & 7 & 18 & 13 & 13 & 55 \\
\hline 18:45 - 19:00 & 2 & 7 & 6 & 7 & 5 & 5 & 43 \\
\hline
\end{tabular}

